\title{
METODOLOGIA CEGA: UMA PROPOSTA DE METODOLOGIA INCLUSIVA
}

\section{Blind methodology: an inclusive methodology proposal}

\section{Zeneide Pereira}

\section{Cordeiro}

Mestra em Políticas

Públicas pelo Programa

de Pós-Graduação em

Políticas Públicas da

Universidade Federal do

Maranhão. Especialista em Gestão e Docência no Ensino Superior. Graduada em Artes Visuais na Universidade Federal do Maranhão. Graduanda em Ciências Econômicas. Integrante do grupo de pesquisa Estado Multicultural e Políticas Públicas da UFMA. Professora da rede de ensino estadual do Maranhão. w.zeneide@gmail.com

O objetivo deste artigo é mostrar a trajetória da primeira estudante de Pós-Graduação com deficiência da Universidade Federal do Maranhão - UFMA. Destacando o processo de construção e execução de uma metodologia de pesquisa acessível para pesquisadores com deficiência visual. Enfatiza várias estratégias de resistência que esta estudante criou para combater a ausência de acessibilidade arquitetônica, comunicacional e atitudinal no ambiente acadêmico.

Palavras-chave: Metodologia; Educação; Resistência.

\begin{abstract}
The purpose of this article is to show the trajectory of the first postgraduate student with disabilities at the Federal University of Maranhão - UFMA. Highlighting the process of building and implementing a research methodology that is accessible to visually impaired researchers. It emphasizes various resistance strategies that this student created to combat the absence of architectural, communicational and attitudinal accessibility in the academic environment.
\end{abstract}

Keywords: Methodology; Education; Resistance

Recebido: julho 29, 2019.

Aceito: maio 13, 2020 


\section{INTRODUÇÃO}

Nesse artigo, relato algumas trilhas da minha trajetória no Programa de Pós-graduação em Políticas Públicas da Universidade Federal do Maranhão. Destaco algumas das inúmeras estratégias que criei, a partir do "senso prático como sentido de um jogo social que se adquire desde a infância participando de atividades sociais" ${ }^{1}$ para que eu pudesse levar a termo minha dissertação em Políticas Públicas².

O processo inicial de elaboração da minha pesquisa se deu a partir de uma série de experimentações, construções e reconstruções de métodos, técnicas e recursos que possibilitassem a acessibilidade

0 processo inicial de elaboração da minha pesquisa se deu a partir de uma série de experimentações, construções e reconstruções de métodos, técnicas e recursos que possibilitassem a acessibilidade a instrumentos que se adequassem à minha condição de pessoa cega. a instrumentos que se adequassem à minha condição de pessoa cega. Nesse processo, inseri conhecimentos que adquiri ao longo da minha vida, de modo empírico, os quais, utilizei primeiramente como formas para desenvolver minha autonomia, mobilidade e compreensão do mundo e em seguida para construir meu objeto de estudo.

Tomei como referência teórica e metodológica a concepção da objetivação participante desenvolvida por Bourdieu (1989). Afinal, havia decidido me debruçar sobre o povo Awá. Os Awá ${ }^{3}$ constituem o povo indígena de contato mais recente no Maranhão e, além daqueles grupos que já foram contatados, existem cerca de 08 grupos isolados $^{4}$, com aproximadamente 110 pessoas. São falantes da "língua Awá, afiliada ao grupo tupi-guarani" ${ }^{5}$.

Para a realização da pesquisa bibliográfica e documental que subsidiaria minha dissertação, trabalhei com a perspectiva do que Cunha denominou etnografia de arquivo ${ }^{6}$. O principal recurso que utilizei foi minha audição e, por meio dela, elaborei mapas mentais com todas as fontes de pesquisa: livros, textos, cartas, mapas cartográficos, entrevistas, documentos oficiais, informações da mídia,

\footnotetext{
${ }^{1}$ BOURDIEU, 2004, p. 81.

${ }^{2}$ CORDEIRO, 2019.

${ }^{3}$ Os Awá são habitantes tradicionais das regiões próximas aos vales dos rios Turiaçu, Capim, Pindaré, Maracaçumé e Gurupi, nos estados do Pará e Maranhão, desde o século XIX. (GOMES, 1985).

${ }^{4}$ Segundo definição da Funai (2018), povos indígenas isolados são aqueles povos indígenas que têm ausência de relações permanentes com a sociedade nacional ou com pouca frequência de interação, seja com não-índios, seja com outros povos indígenas.

${ }^{5}$ MONSERRAT, 1994.

${ }^{6}$ CUNHA. 2004, p. 291.
} 
músicas, filmes e vídeos. Interliguei informações que adquiri no decorrer da minha vida sobre meu objeto, com experiências pessoais e com conhecimentos que adquiri na academia.

Portanto, os conhecimentos teóricos e práticos, eruditos e científicos que acumulei no decorrer da minha história de vida foram essenciais para construção teórica metodológica da minha pesquisa.

\section{VER DEMAIS, CEGA TAMBÉM!}

Ingressei no Programa de Pós-Graduação em Políticas Públicas da Universidade Federal do Maranhão em março de 2017, com o objetivo de pesquisar as primeiras relações de contato que ocorreram entre os Awá e os brasileiros, no período de 1960 a 1990, no estado do Maranhão - Brasil.

As primeiras informações que adquiri sobre os Awá foram na minha infância, contadas principalmente, pelo meu avô e que remetiam para o fato de eu ser neta de uma Awá7.

Os Awá que já foram contatados ${ }^{8}$ habitam uma região conhecida como "pré-Amazônia maranhense, na fronteira entre o Maranhão e o Pará", em três terras indígenas: Terra indígena Carú, Terra indígena Alto Turiaçu e Terra indígena Awá, todas demarcadas ${ }^{9}$.

Antes de serem contatados, os Awá viviam exclusivamente como caçadores e coletores, "deslocando-se em pequenos grupos de 08 a 30 pessoas. Espalharam-se pelo Maranhão Amazônico desde 1850, e a partir de 1960 foram contatados por não indígenas" ${ }^{10}$.

Quando ingressei no Programa de Pós-Graduação em Políticas Públicas, estava num processo de perda de visão agressivo e dolorido.

\footnotetext{
${ }^{7}$ A história que mais chamou minha atenção foi sobre um resgate de uma menina, supostamente Awá, que ocorreu mais ou menos, no final da década de 1940, logo que meu avô chegou ao Maranhão, vindo de Jati, um município do estado do Ceará. Algum tempo depois, essa menina se tornou sua esposa.

${ }^{8}$ Segundo a Funai (2018) povo recém-contatado, são aqueles povos ou grupos indígenas que mantêm relações de contato permanente e/ou intermitente com segmentos da sociedade nacional e que, independentemente do tempo de contato, apresentam singularidades em sua relação com a sociedade nacional e seletividade, autonomia na incorporação de bens e serviços. São, portanto, grupos que mantêm fortalecidas suas formas de organização social e suas dinâmicas coletivas próprias, e que definem sua relação com o Estado e a sociedade nacional com alto grau de autonomia

${ }^{9}$ HERNANDO, et al., 2013, p. 25.

${ }^{10}$ GOMES, 2012, p. 227.
} 
Sentia fortes dores e inflamações nos olhos, enxaqueca, dores de ouvido e a minha mobilidade estava extremamente comprometida.

Diariamente, meu esposo me levava para assistir aula. Chegávamos cedo, para que ele pudesse me ensinar a conhecer e andar sozinha no prédio em que estudava. O objetivo disso, era melhorar minha mobilidade no curso e na universidade. Durante as aulas, minhas dificuldades eram imensas, não conseguia acompanhar as leituras e nem as discussões em sala. Os recursos que facilitavam meus estudos, que eu tinha em casa, eram insuficientes. Em razão disso, busquei outras estratégias. Primeiramente, pedi um vídeo ampliador ${ }^{11}$ na coordenação do curso, o que foi me concedido cerca de dois meses depois. Meu direito de uso desse equipamento era somente nas dependências do Programa de Pós-Graduação em Políticas Públicas.

Assim, eu tinha apenas um turno para usar o vídeo ampliador, porque, em outro turno eu estava em sala de aula. O resultado é que eu nunca conseguia fazer todas as leituras necessárias. Pedi aos professores e professoras que disponibilizassem a ementa da disciplina com antecedência, mas, muitos esqueciam e não me enviavam. Passei a pedir na coordenação mas, na maioria das vezes não me enviavam, ou enviavam um documento em formato de imagem ${ }^{12}$, no qual eu não conseguia ler. Comecei a gravar as aulas, mas, nessa época, a sensibilidade da minha audição prejudicava o entendimento de alguns sons, principalmente, da voz humana.

Percebi que todas as estratégias que havia criado para facilitar meus estudos e garantir minha permanência no curso fracassaram ao ponto de pensar que a única solução racional e viável seria o trancamento ou abandono. Porém, resisti buscando permanecer no curso. Tomei como referência a noção de estratégia desenvolvida por Bourdieu ${ }^{13}$ no sentido de que estratégia é um instrumento de ruptura com o ponto de vista objetivista e com a ação sem agente, sendo, portanto, um produto do sentido prático do jogo social, em que o

\footnotetext{
${ }^{11}$ Também chamado de lupa de mesa, é uma lupa que tem uma tela semelhante a de um computador de mesa e funciona ligada a energia. O vídeo ampliador aumenta a fonte até 1.000 vezes.

${ }^{12}$ Eu nunca pude identificar imagens visualmente e os recursos, aplicativos leitores de tela que utilizo não leem imagem. É necessário que uma pessoa vidente descreva a imagem para que eu entenda.

${ }^{13}$ BOURDIEU, 2004.
} 


No meu caso,
percebi que seria
necessário criar
estratégias que
me adequassem
ao jogo social
realizado na
universidade.
Estava explícito
que eu era a
figura "aversa"
em relação aos
agentes que
estavam inseridos
nesse jogo.

No meu caso, necessário criar estratégias que me adequassem aojogo social realizado na universidade. Estava explícito que eu era a figura "aversa" em relação aos nesse jogo. bom jogador está inventando permanentemente para se adaptar a situações variadas e nunca idênticas.

No meu caso, percebi que seria necessário criar estratégias que me adequassem ao jogo social realizado na universidade. Estava explícito que eu era a figura "aversa" em relação aos agentes que estavam inseridos nesse jogo. Meu processo de produção científica era extremamente diferente dos deles. Além disso, existiam enormes barreiras físicas e emocionais pelo fato de eu não enxergar. O fato de procurar estratégias para me inserir nesse jogo, não significa que eu decidi seguir todas as regras ou participar das mesmas disputas que os demais participantes, pois, no meu caso, isto seria impossível, porque, "naturalmente", eu já estava numa condição de extrema desigualdade de condição. Porém, procurei em alguns momentos fazer o jogo duplo, agindo de acordo com meus interesses ao mesmo tempo que mantinha as aparências de obediência às regras. Bourdieu chama "jogo duplo" ${ }^{14}$, a estratégia que permite produzir uma infinidade de lances possibilitados pelo jogo.

Nesse sentido, decidi falar sobre minhas limitações e sobre minha deficiência. No momento em que falava, algumas pessoas demonstravam compaixão e me auxiliavam principalmente, na mobilidade, só que este auxílio ocorria somente no momento em que havia terminado de falar das minhas limitações. Diariamente, ouvia falas e vivenciava atitudes que intensificavam minha exclusão no curso e na própria universidade.

Posteriormente, várias pessoas que estudaram comigo no mestrado me falaram que no decorrer do curso evitaram se aproximar de mim com medo de se tornarem minhas guias. Outras me relataram que não sabiam como falar comigo, porque tinham medo e pena de mim, imaginavam que no meu dia a dia eu dependeria totalmente de uma pessoa vidente, etc.

Percebo, nos dias de hoje, que muitas das pessoas que contribuíram para minha exclusão no mestrado a partir de crenças pré-construídas ${ }^{15}$ de modo preconceituoso, egoísta e discriminatório, continuam a pôr em prática as mesmas atitudes. Atitudes essas, que são reatualizadas com novas concepções expressas em frases como: "você

\footnotetext{
14 BOURDIEU, 2004, p. 81.

${ }^{15}$ No sentido proposto por BOURDIEU, 1989.
} 
é cega mais é inteligente". "Você nem parece ter deficiência, tem certeza que é cega mesma"? "É incrível o que você faz, é claro que você é uma exceção"!

Frases desse tipo são corriqueiras no meu cotidiano e, a meu ver, mostram preconceitos construídos historicamente, os quais, as pessoas evitam tornar públicos de modo explícito, mas que sempre o fazem camuflados com expressões de dor e sentimentalismos exacerbados. São efetivados por meio de crenças pré-construídas que podem ocasionar atitudes de intolerância e violência física e simbólica ${ }^{16}$ com pessoas ou grupos de pessoas numa determinada sociedade.

Moreno ${ }^{17}$ afirma que a exclusão é um conceito que tenta definir teoricamente a realidade social que enfrentamos na prática do viver cotidiano e isto, supõe uma aceitação evidente de uma divisão entre dois setores muito distintos de uma sociedade.

No meu caso, a experiência de exclusão que vivenciei na pós-graduação não foi novidade alguma, pois, vivo situações semelhantes diariamente, desde a infância. Muitas ocorrem em decorrência de ser oriunda de uma região com precária situação econômica, pela falta de estrutura familiar, pela ausência de educação escola. Outras situações de exclusão que vivenciei ocorreram em razão do meu gênero, da cor e da minha deficiência.

Portanto, desde minha infância percebo que sempre vivi num mundo social dividido. Mesmo quando participo de um determinado grupo, como por exemplo, uma turma de pós-graduação numa universidade federal. "A exclusão por si mesma não pressupõe necessariamente desigualdade, mas somente quando, como em nosso caso, a exclusão se exerce sobre condições de vida humana"18.

Em razão de inúmeras atitudes de exclusão, expressas sobretudo pela ausência de acessibilidade atitudinal e comunicacional ${ }^{19}$, estudei dois semestres isolada socialmente e sem acesso a maior parte dos conteúdos trabalhados em sala de aula. A maioria das

\footnotetext{
${ }^{16}$ No sentido proposto por BOURDIEU, 2007.

17 MORENO, 2005.

18 MORENO, 2005, p. 96.

${ }^{19}$ Vivenciei todos os tipos de ausência de acessibilidade na de pós-graduação mas, as que mais me prejudicaram foram a ausência de acessibilidade atitudinal e comunicacional.
} 
referências não estavam disponíveis em formato acessível. Os slides, filmes e vídeos quando eram projetados em sala não tinham audiodescrição.

Durante uma dessas aulas sem nenhuma acessibilidade atitudinal, comunicacional e social, na qual eu era simplesmente invisível aos olhos dos que enxergam, falei em tom irônico e enfático: "só resistindo como uma mulher cega" para sobreviver aqui! Percebi que esta frase "chocou" algumas pessoas e, principalmente, a professora. Após esse episódio passei a falar com mais frequência. No segundo semestre de 2018, quase às vésperas das eleições presidenciais, quando estavam sendo organizadas diversas mobilizações políticas e sociais em São Luís, fiz duas camisetas com a frase: resista como uma mulher cega! Passei a vestir na universidade, durante diversas mobilizações, apresentações de trabalhos e eventos dos quais participei nessa época.

\section{RESISTA COMO UMA MULHER CEGA}

Nas vésperas do dia do índio do ano de 2018, perdi meu resquício visual e fiquei cega total. Com isso, precisei criar novas formas de reorganização em âmbito familiar, social e acadêmico, de modo que eu pudesse continuar executando minhas atividades no mestrado.

A cegueira me obrigou a aprender, a ver e a viver no mundo de uma forma diferente. Tudo o que havia aprendido antes desse momento, passou a não ter valor algum. No meu novo mundo não havia vida, formas, cores e movimento. Existia apenas um som estridente que me fazia pensar que estava no vácuo, perdida. Em razão disso, necessitei fazer reabilitação para reaprender coisas simples do dia a dia como: andar, comer, falar, vestir e ser alfabetizada novamente. Passei a frequentar a escola de cegos do Maranhão e, na minha convivência com pessoas cegas e com outros tipos de deficiência, aprendi rapidamente andar com bengala, a falar localizando pessoas pela voz, a ter noção espacial e andar com acompanhante. Mas, o que "revolucionou" minha vida foi quando conheci uma infinidade de aplicativos que pessoas cegas podem utilizar para ler, escrever, pesquisar, utilizar redes sociais, auxiliar na mobilidade, reconhecer cores, formas e localizações. 
Primeiramente, aprendi a usar o celular com o leitor de tela. Através desse recurso, pesquisei na internet técnicas de leitura e escrita de trabalhos acadêmicos para pessoas cegas e encontrei muitas informações que me facilitaram a utilizar leitores de telas no computador. Instalei diversos aplicativos no meu celular e no meu computador e, em poucas semanas havia aprendido a digitar e ler cerca de dez vezes mais rápido do que quando tinha baixa visão.

Paradoxalmente, quando fiquei cega total, em alguns momentos as inúmeras situações de exclusão que vivenciei se intensificaram, ao mesmo tempo em que consegui criar diversas estratégias de resistência ${ }^{20}$ para fugir da exclusão social na sala de aula e vencer o isolamento social.

Nesse período, numa disciplina foi decidido que o trabalho de conclusão seria um seminário, que deveria ser apresentado em equipe de pelo menos duas pessoas. No momento em que ocorreu a organização dos grupos, não me esforcei para integrar nenhum, devido a uma situação extremamente desagradável que havia vivenciado em outra disciplina, na qual, ouvi algumas estudantes falando que temiam ficar comigo na mesma equipe porque, minha participação poderia prejudicar a nota de todas.

Decidi então pesquisar as referências, para que eu tivesse tempo de pedir auxílio, caso não encontrasse em formato acessível. O objetivo principal era eu encontrar referência acessível para estudar e apresentar um seminário sozinha. Um dia, uma estudante do doutorado falou-me que estava sem equipe e respondi que também estava, mas que iria fazer meu trabalho sozinha. Imediatamente, ela falou: "pois, iremos fazer o seminário juntas". Depois que apresentamos o seminário ela me convidou para tomar um café.

Na semana seguinte, passei a ser "percebida" por alguns colegas. Alguns deles, motivados por não ficarem na fila do restaurante universitário se estivessem em minha companhia, convidaram-me para almoçar. Outras pessoas, também visando agilizar

\footnotetext{
${ }^{20}$ Nesse período criei uma espécie de campanha com o título: Resista como uma mulher cega! Com o objetivo de criar de divulgar questões relacionadas a invisibilidade da mulher cega no meio acadêmico, questões de gênero e direitos humanos. Atualmente, criei um site com o mesmo nome da campanha, nele público textos sobre diferentes temas: povos indígenas, democracia, política, gênero, etc. Disponível em: https://resistacomoumamulhercega.home. blog/category/sobre-nos/
} 
o atendimento, pediam para eu pegar livros emprestados na biblioteca. Recebi outras demandas desse tipo e acatei-as, numa estratégia de estabelecer uma relação de trocas. Paguei contas e comprei ingressos, ações que me possibilitaram companhias para além da universidade.

Em razão dessas minhas "gentilezas", em poucos meses acumulei um grupo considerável de pessoas ao meu lado, que por vezes me auxiliavam na mobilidade, nas leituras dos textos. Além disso, scaneavam textos para mim, faziam audiodescrição de imagens e vídeos e ajudavam-me a assinar meu nome nas cadernetas de frequência, conduzindo minha mão ao local exato onde deveria firmar minha assinatura. Com isso, meu esposo passou somente a me levar e buscar na universidade, deixando de me acompanhar diariamente, do início ao fim das aulas, como fazia anteriormente, quando ingressei no curso.

No terceiro semestre do curso já estava reabilitada, embora, tivesse dificuldades de locomoção. Nesse período, fiquei mais próxima do meu esposo e da minha orientadora. Essas relações me proporcionaram segurança emocional para que eu pudesse retornar para as aulas e dar continuidade a minha pesquisa. Tornou-se frequente no meu dia a dia responder inúmeras perguntas, que nem sempre eram gentis, de pessoas na universidade e na sociedade em geral sobre minha vida acadêmica e pessoal. Recebi diversos convites para participar de mesas redondas, palestras e ventos na universidade escolas, movimentos sociais, associações de bairro, partidos políticos, instituições públicas e privadas para falar sobre a minha história de vida e sobre minha pesquisa.

Nesse momento, concentrei-me, principalmente, nas atividades do curso e na elaboração da minha dissertação e, também, em questões relacionadas a minha "nova condição". Em alguns momentos, pensei que deixar de ter baixa visão e ser cega total, foi como se eu estivesse ganhado "super-poderes", porque passei a decorar informações como citações e referências muito rapidamente, passei ouvir e reconhecer sons a longas distâncias, o que facilitou minha mobilidade e compreensão de espaços, passei a ler e escrever mais rápido. Deixei de perceber situações de exclusão que ocorriam comigo porque meu foco era outro. 


\section{METODOLOGIA CEGA}

Como afirmei anteriormente, quando fiquei cega direcionei meu foco para poucas coisas. A primeira delas foi aprender tarefas manuais cotidianas (cozinhar, cuidar de uma horta, etc.), a segunda foi elaborar minha dissertação.

Dediquei-me a pesquisar formas que facilitassem a escrita da minha pesquisa, mas não encontrei nenhuma referência que indicasse técnicas ou metodologias de pesquisa específicas para serem utilizadas por pesquisadores cegos. Enfrentei um dilema, sobre como

Utilizei na minha
metodologia
uma série de
conhecimentos
que tive que
adquirir logo que
me tornei uma
pessoa cega,
como me localizar
nos espaços e
melhorar minha
mobilidade como
a memorização
de inúmeros sons, formas, espaços, gostos, cheiros e sensações. fazer minha dissertação sem perder o rigor científico e ao mesmo tempo sem ter condições práticas totalmente acessíveis de leitura e escrita. Os leitores de tela não reconhecem imagens, alguns formatos de documentos, gráficos, palavras e, além disso, tinha muitas dificuldades para formatar um documento, inserir citações, notas, referências, tabelas, corrigir palavras e localizar algum conteúdo no texto. Com isso, percebi que necessitava encontrar minha própria forma de leitura e escrita.

Lembrei-me que fui alfabetizada de forma oral ${ }^{21}$ através de meus familiares. Foi somente, depois de alguns anos que ingressei numa escola multiseriada em Maranhãozinho ${ }^{22}$. Nessa época, em razão da minha pouca visão, não conseguia relacionar os sons das palavras com sua forma escrita, por isso, demorei aprender a escrever. Foram essas lembranças e experiências que acumulei ao longo da minha vida, que facilitaram meu processo de alfabetização e conhecimento do mundo, que tomei como a principal referência para desenvolver uma metodologia que facilitasse a realização da minha pesquisa.

Utilizei na minha metodologia uma série de conhecimentos que tive que adquirir logo que me tornei uma pessoa cega, como me localizar nos espaços e melhorar minha mobilidade como a memorização de inúmeros sons, formas, espaços, gostos, cheiros e sensações. $\mathrm{Na}$ medida em que inseria esses meus conhecimentos, busquei experimentar inúmeros recursos de acessibilidade específicos para pessoas cegas, principalmente aplicativos leitores de tela e grava-

21 Minha alfabetização ocorreu nos momentos de descanso e nas horas de almoço do trabalho dos meus familiares na roça ou nos currais nos finais de tarde, quando nós buscávamos estrume para a plantação. Meus primeiros lápis foram gravetos e galhos finos de árvores e meus primeiros cadernos, por muito tempo, foi apenas o chão.

22 Município do Maranhão localizado próximo do rio Maracaçumé. 
dores de som. Esses recursos, além de facilitarem meu trabalho me proporcionaram maior autonomia ${ }^{23}$ e segurança no dia a dia.

No decorrer da minha pesquisa, e desde o processo de construção do objeto, estive em constante processo de "construção e reconstrução ${ }^{24 "}$ de técnicas e utilização de recursos. Relacionei categorias teóricas com memórias e experiências que vivenciei na infância, sobre a história do povo Awá25.

Tomei como referência teórica e metodológica a concepção da objetivação participante desenvolvida por Bourdieu ${ }^{26}$ no sentido de requerer uma ruptura das aderências e das adesões mais profundas e mais inconscientes, justamente aquelas que, muitas vezes, constituem o interesse do pesquisador no próprio objeto de estudo, tudo aquilo que ele menos pretende conhecer na sua relação com objeto é o que ele procura conhecer.

Para a realização da pesquisa bibliográfica e documental trabalhei com a perspectiva do que Cunha ${ }^{27}$ denominou etnografia de arquivo, uma "modalidade de investigação antropológica que toma determinados conjuntos documentais, mais especificamente as coleções e os arquivos pessoais [...]. Para uma compreensão crítica acerca das formas de produzir histórias".

Para trabalhar com fontes audiovisuais, utilizei um assistente de voz e um ledor de tela no celular. Quando eu estava assistindo a um filme ou vídeo, aproximava o celular do assistente de voz e o áudio era convertido em texto. Em seguida, bastava somente salvar no Drive ou no E-mail.

O principal recurso que utilizei foi minha audição e por meio dela, elaborei mapas mentais com todas as fontes de pesquisa: livros, textos, cartas, mapas cartográficos, entrevistas, documentos oficiais, informações da mídia, músicas, filmes e vídeos. Interliguei informa-

\footnotetext{
${ }^{23}$ Compreendo a autonomia de pessoas cegas como uma série de características que cada uma desenvolve historicamente a partir da sua interação social e o com o meio ambiente.

${ }^{24}$ Bourdieu, Chamboredon e Passeron afirmam que "a investigação nunca se reduz a uma simples leitura do real, por mais desconcertante que seja, já que pressupõe sempre a ruptura com ele mesmo e com as configurações que ele propõe a percepção" (BOURDIEU; CHAMBOREDON; PASSERON, 1999, p. 25).

${ }^{25}$ Essa atitude, se deu sobretudo, em razão da minha condição e identidade de mulher cega, que me obrigou a vivencias um processo continuo em busca de recursos que facilitassem minha leitura, escrita e interpretação de informações.

${ }^{26}$ BOURDIEU, 1989, p. 51.

27 CUNHA, 2004, p. 291.
} 
ções que adquiri no decorrer da minha vida sobre meu objeto, com experiências pessoais e com conhecimentos que adquiri na academia. Decorei citações, frases e categorias. Fiz muitas notas e gravei muitos áudios sobre a estrutura dos capítulos.

Para a realização da escrita utilizei um computador e um celular, com vários aplicativos ledores de tela ${ }^{28}$ e gravadores de voz. Utilizei principalmente, o ledor de tela NVDA para digitar e formatar textos no Word. O maior problema que enfrentei durante a digitação, quando utilizava este aplicativo, foi com a correção gramatical e com a leitura de tabelas ${ }^{29}$.

Pelo fato de não enxergar, a correção de uma simples palavra, podia levar muitas horas, sem contar que, muitas vezes, o ledor trava, reinicia, o documento fecha e no pior das situações, uma página ou o documento inteiro é perdido.

O NVDA não reconhece alguns formatos de documentos e sites de pesquisa. Por isso, utilizei o narrador do Windows 10 para realizar pesquisas na internet, ler jornais, livros e textos online.

Para amenizar problemas de digitação e correção gramatical, utilizei meu celular com o ledor de tela Talk Back e o assistente de voz do Google para escrever. O processo ocorreu da seguinte maneira: por meio do Talk Back, abria um novo documento no Word e em seguida o assistente de voz, no momento em que estava ouvindo a leitura de um documento no computador, eu falava/ repetia para o assistente de voz citações curtas, frases, explicações e categorias e imediatamente meu áudio era convertido em texto. Depois, restava somente salvar o documento no Drive e baixar no computador para utilizar quando precisasse na pesquisa. Esse recurso, possibilita a escrita de uma palavra na maneira em que é falada, mas, não garante que a escrita seja feita corretamente. Assim, é sempre necessário que seja feita uma correção por pessoas que enxergam.

Utilizei o Dosvox para ler documentos em PDF, embora, tenha sido com menos frequência. Meu uso desse recurso ocorreu no momento da organização de pastas de documentos que utilizaria durante

\footnotetext{
${ }^{28}$ Utilizei o NVD para leitura e escrita em documentos no formato Word e PDF, usei também, o Dosvox para leitura em PDF e o narrador do Windows 10 para leitura e pesquisa na internet.

${ }^{29}$ Este aplicativo permite fazer e ler tabela, mas quando estava fazendo a dissertação eu ainda não sabia utilizar este recurso. Por isso, tive muita dificuldade.
} 
a escrita da dissertação no meu computador e num HD externo. Fiz notas e fichamentos de todos os autores que estudei e organizei as informações em pastas separadas. Por exemplo, uma pasta de documentos de Pierre Bourdieu, outra de João Pacheco de Oliveira, outra de Elizabeth Coelho, etc.

Em todos os momentos da elaboração da minha pesquisa, utilizei estes recursos simultaneamente. No que se refere a pesquisa empírica, fiz uma entrevista pessoal e duas entrevistas por meio de redes sociais e um gravador de voz.

A entrevista pessoal ocorreu com Sidney Possuelo ${ }^{30}$, como uma estratégia de buscar mais uma versão sobre o contato realizado com os Awá. Desta feita, pude obter uma versão de alguém que havia sido parte do processo, que falava do lugar de quem tinha autoridade para fazer a atração de índios isolados, conferida pela Funai. A entrevista com Possuelo girou em torno do seu primeiro contato com os Awá, que teria ocorrido no local que hoje está localizado o posto indígena Juriti. Fiz essa entrevista junto com minha orientadora, a antropóloga Elizabeth Coelho e com a antropóloga Josy Silva.

No decorrer da sua fala direcionei meu foco para o modo como Possuelo narrava sua experiência de contato, dedicando minha atenção ao seu tom de voz, com o objetivo de perceber em quais situações ele demonstrava mais emoção e insatisfação, a sua opinião a respeito dos contatos com os Awá, o que pensava e o que pensa sobre a política indigenista brasileira. A apreensão desses elementos foi importante para compreender o que ele dizia para, enfim, construir meus próprios significados e pontos de vista. Em determinados momentos da entrevista, percebi que Possuelo detalhava alguns fatos ocorridos, o que me causou a impressão, de que ele estava revivendo emoções que há muito tempo não vivia, como o encontro de Karapiru com seu filho, que ocorreu na sua casa ${ }^{31}$. A entrevista de Possuelo foi gravada e recebi auxílio da Elizabeth Coelho para transcrição das informações que utilizei na minha pesquisa.

\footnotetext{
${ }^{30}$ Possuelo atualmente, é sertanista aposentado da Funai, e liderou a equipe de atração para contatar o segundo grupo Awá, na Terra indígena Alto Turiaçu.

${ }^{31}$ Karapiru, um Awá dado como desaparecido, foi resgatado por Possuelo, quando vivia em um povoado na Bahia, após fugir da perseguição dos invasores das terras Awá.
} 


\section{0 resultado dessa estratégia de pesquisa foi excelente. Quando as lembranças Ihes ocorriam, enviavam-me o áudio com muito entusiasmo. Descreviam locais, pessoas e objetos, que quase sempre vinham acompanhadas de termos como você não lembra disso?}

Entender a forma como são ditas as informações é de extrema importância para mim, porque facilita minha compreensão sobre um determinado tema de modo mais amplo. Assim, quando estivesse ouvindo a gravação da entrevista de Possuelo, lembraria de detalhes que podiam não estar explícitos no áudio.

Busquei informações sobre o contato da minha família com os Awá que provavelmente, teria ocorrido no final da década de 1940, próximo da cabeceira do rio Maracaçumé no Maranhão. A senhora Bárbara, que foi minha mãe de criação durante alguns anos, tornou-se minha grande interlocutora. Ela tinha um lote de terra "nas Vinte", próximo do local de onde meu avô morava quando supostamente, encontrou minha avó na mata. Também obtive relatos da minha tia Ana, que morou em Maranhãozinho até 1990 e que, também, tinha lotes de terra "nas Vinte" ${ }^{32}$.

Minha entrevista com Barbara e com a tia Ana ocorreram de modo semelhante. Primeiramente, solicitei por meio de conversas por telefone que me contassem as lembranças que tinham das suas experiências ou histórias que tinham vivenciado ou escutado sobre os Awá e outros indígenas.

Inicialmente, percebi que elas contavam a mesma história em diversas formas e as vezes, não lembravam do que tinham dito e diziam que tal coisa não teria existido. Descobri que as variações em suas informações decorriam muito em razão do momento emocional em que elas estavam no momento em que conversávamos. Assim, numa ocasião narravam uma história em tom de saudosismo e em outro momento em tom de revolta. Decidi sugerir a elas que quando tivessem tempo ou quando se lembrassem de algo referente a minha pesquisa, me enviassem um áudio ou uma mensagem escrita, no dia e horário que quisessem.

O resultado dessa estratégia de pesquisa foi excelente. Quando as lembranças Ihes ocorriam, enviavam-me o áudio com muito entusiasmo. Descreviam locais, pessoas e objetos, que quase sempre vinham acompanhadas de termos como você não lembra disso? Você sempre ia nesse lugar com teu avô, ou então, tu lembras de dona

\footnotetext{
${ }^{32}$ Entrevistei somente dona Barbara e tia Ana porque quando iniciei, os primeiros passos para a elaboração desse estudo, a maioria das pessoas que me haviam relatado histórias de contato com os Awá ou com outros índios que habitavam regiões próximas do rio Maracaçumé e da Reserva Florestal do Gurupi, haviam falecido.
} 
Mundica? Aquela? Recebi muitos áudios e mensagens, alguns não se referiam ao meu objeto de pesquisa, mas, a minha própria vida quando morava nas Vinte e em Maranhãozinho.

Através dos áudios compreendi os relatos e a forma de como os relatos eram feitos. Através de suas vozes, compreendia em uma única mensagem, muitos e diferentes significados. Pude ouvi-los, inúmeras vezes, sem perder nenhuma informação, inclusive, aquelas que não são ditas, mas que são expressas na entonação da voz e nas emoções, algo que não seria possível por meio de ligações telefônicas e nem mesmo numa entrevista pessoal. Havia percebido anteriormente que neste caso, o conteúdo e a "essência" da mensagem mudam de acordo com emoções e situações em que a pessoa se encontra.

Por diversas razões (tempo escasso, limitações da deficiência visual e financeiras) não fiz pesquisa de campo diretamente com os Awá e nem com moradores que participaram de levas migratórias para o território desse povo.

Com base, nas falas da dona Barbara e da tia Ana, compreendi questões relacionadas a localização geográfica, características físicas, sociais e territoriais dos Awá e dos moradores próximos do território de mobilidade do povo Awá. Obtive uma versão de como seriam as relações de contato desse povo com os imigrantes que chegaram nas regiões próximas do rio Maracaçumé e da Reserva Florestal do Gurupi, motivados por projetos de colonização estatal e pela extração de madeira ilegal. Esses relatos facilitaram a minha compreensão acerca das ações da Fundação Nacional do Índio - Funai, descritas em relatórios antropológicos que foram elaborados pelo antropólogo Mércio Gomes e pela antropóloga Elizabeth Coelho, sobre o contato com os Awá.

No decorrer das minhas conversas com a Barbara e com a tia Ana, sempre ouvia expressões como, "coitadinhos", "bichinhos" e "gente inocente, sem maldade nenhuma". Estas expressões muitas vezes eram seguidas de um acontecimento em que os Awá se encontravam ameaçados de violência, morte e sequestros de crianças. Em relação aos sequestros de crianças, elas me afirmaram que não eram sequestros, mas sim, um resgate, um salvamento. Afirmavam, em tom de questionamento: que futuro uma criança poderia ter perdida na 


Minha
preocupação foi
mostrar dados
coerentes nesses
relatos que
caracterizam o
contexto em que
ocorreram. Pude
identificar como
os primeiros
contatos entre
os Awá e os
brasileiros se
deram e as
relações entre
os Awá e os
moradores
de povoados
construídos
em territórios
tradicionais
desse povo.

mata, correndo o risco de bicho comer ou até mesmo da mãe d'água levar? Esta era vista como uma solução benéfica. Muitos moradores de povoados próximos das áreas de mobilidade dos Awá, organizavam armadilhas para "resgatar" ou "salvar" crianças Awá. Isto para eles, era uma atitude de generosidade, porque estavam evitando que uma criança crescesse no meio do mato, sem terra e sem família.

Minha preocupação foi mostrar dados coerentes nesses relatos que caracterizam o contexto em que ocorreram. Pude identificar como os primeiros contatos entre os Awá e os brasileiros se deram e as relações entre os Awá e os moradores de povoados construídos em territórios tradicionais desse povo. Esse processo não foi fácil, porque precisei relativizar conhecimentos do "senso comum: um mundo de evidências partilhados por todos e que garante nos limites de um universo social, um consenso primordial sobre o sentido do mundo, um conjunto de lugares comuns" ${ }^{\prime 3}$, para construir um conhecimento científico, coerente.

Os relatos de dona Barbara e da tia Ana foram para mim fontes de informação e conhecimento a partir das suas experiências de vida, nas quais eu estava inserida em diversos momentos. Assim, levei em consideração, aspectos culturais, sociais e místicos.

Em diversos momentos da elaboração da pesquisa revivi emoções, sensações, medos, histórias e curiosidades da minha infância, que provocavam lembranças de informações sobre os Awá, as quais, tinha escutado pela voz dos meus familiares, principalmente, dos causos contados pelo meu avô sobre "índios", encantados, alma penada e a natureza. Cheguei até ficar com os pelos eriçados ao lembrar do medo que tinha de ser pega pela mãe' d'água. Em alguns momentos, sentia-me em baixo das mangueiras ouvindo $o$ som das folhas balançadas pelo vento, ouvia as gaitadas ${ }^{34}$ demoradas, minhas e dos meus irmãos, enquanto corríamos nos caminhos estreitos e lameados das Vinte, o revoar das curicas, o canto dos periquitos no beiral do nosso alpendre, o cheiro das ervas usadas pela minha avó durante a preparação de banhos. Sentia a energia de muitos e muitos benzimentos que recebi, o cheiro da minha rede, do arroz pilado, do cuscuz feito no prato, dos sucos de murici...

\footnotetext{
33 BOURDIEU, 2007, p. 118.

34 Sorrisos, risadas
} 
Essas minhas experiências me aproximaram do meu objeto de estudo. O momento da escrita da dissertação foi como se eu estivesse conectada com o mundo espiritual, no qual minhas mãos passaram a ser guiadas por seres celestes e, minha ausência de visão não teve mais importância. Meu passado e o meu presente se encontraram e os conhecimentos que adquiri a partir de crenças, misticismo, relações sociais e com a natureza desde minha infância, foram o ponto de partida para compreender conhecimentos científicos pautados em teorias e técnicas metodológicas.

Quando estava realizando a pesquisa os Awá e o mundo dos Karaiw

Quando estava realizando a pesquisa os Awá e o mundo dos Karaiw compreendi minha deficiência visual como um elemento definidor da minha identidade. Essa compreensão foi essencial para meus posicionamentos políticos, sociais e intelectuais na universidade. compreendi minha deficiência visual como um elemento definidor da minha identidade. Essa compreensão foi essencial para meus posicionamentos políticos, sociais e intelectuais na universidade. Definiu e traçou o percurso da minha investigação científica e do meu "lugar de fala" no Programa de Pós-Graduação em Políticas Públicas - PPGPP

Porém, recentemente passei a perceber que minha vida foi e é direcionada por uma série de elementos e a minha deficiência é apenas um deles. Além, disso, entendo que minha deficiência não é a única responsável por definir minha vida e, portanto, minha identidade, embora, socialmente, seja minha deficiência um elemento de destaque, pelo qual me identifico, individualmente.

O papel da minha orientadora foi indispensável nesse momento, pois, além das orientações para organização e elaboração do material da pesquisa, pude contar com seu auxílio na acessibilidade e na busca de recursos. Em diversos momentos ela leu e transcreveu documentos e áudios para que eu pudesse utilizar as informações. Além do seu auxílio, pude contar também, com o de inúmeras pessoas, como meu esposo, que leram textos e foram minhas guias, diariamente.

Assim, a elaboração da minha dissertação se deu a partir de uma metodologia construída a partir de fundamentos teóricos metodológicos, mas, sobretudo, a partir de experiências e conhecimentos que adquiri enquanto pessoa cega. Considero este processo como uma metodologia cega, por ser possível com o uso de recursos e estratégias desenvolvidas e utilizadas por pessoas cegas no seu cotidiano. Neste processo, o visível não tem lugar, os pensamentos, 
ideias, crenças, conceitos, práticas e estereótipos pré-construídos e historicamente definidos são postos em questão continuadamente. É necessário constante experimentação e uma invenção permanente que se adeque a condição do agente que pesquisa para só assim, realizar a pesquisa.

Em todas as fases da minha pesquisa estive em constante experimentação de recursos, construção e reconstrução de informações, descobertas de habilidades que favoreciam minha autonomia física e intelectual.

A elaboração de toda minha pesquisa ocorreu simultaneamente, isto é, não fiz por partes ou capítulos. Depois que todo o conteúdo foi escrito, organizei com o auxílio da minha orientadora as partes, elementos pré-textuais, pós-textuais. Na minha cegueira, pude tornar visíveis fragmentos dos contatos dos Awá com os brasileiros.

\section{CONSIDERAÇÕES FINAIS}

Meu objetivo nesse artigo foi relatar experiências que vivenciei e mostrar algumas "estratégias de resistência que criei para permanecer e concluir o curso de mestrado em Políticas Públicas, após ter perdido a visão.

Meu processo metodológico, bem como a construção do objeto de pesquisa, ocorreu a partir da compreensão de pontos de vista diversos, incluindo, minhas experiências e compreensão empírica, enquanto pessoa com deficiência visual, as quais, foram construídas socialmente e historicamente por meio de histórias repletas de fantasia, crenças e misticismo, que conduziram e conduzem minha vida nos dias de hoje. Em todas as fases da pesquisa estive em constante processo de construção e reconstrução de técnicas, recursos, fontes, categorias e perspectivas teóricas.

Espero que a maneira que encontrei para realizar minha pesquisa possa contribuir para que diversos pesquisadores, em específico, pessoas cegas, possam construir as trilhas de conhecimento nos meandros da escuridão. Acredito que, muitos dos recursos que utilizamos para facilitar a nossas atividades do dia a dia podem ser empregados como recursos de pesquisa científica. 


\section{REFERÊNCIAS}

BOURDIEU, Pierre. O Poder Simbólico. Lisboa: Difel, 1989.

BOURDIEU, Pierre. Coisas ditas. São Paulo. Brasiliense, 2004.

BOURDIEU, Pierre. Meditações Pascalianas. Rio de Janeiro.

Bertand, 2007.

BOURDIEU, Pierre. PASSERON, Jean-Claude. A reprodução: elementos para uma teoria do sistema de ensino. Covilhã, Lusofia, 2009.

CORDEIRO, Zeneide Pereira. Os awá e o mundo dos karaiw. (Dissertação de mestrado). Programa de Pós-Graduação em Políticas Públicas - UFMA, São Luís, 2019.

CUNHA, Olívia Maria Gomes da. Tempo imperfeito: uma etnografia do arquivo. MANA 10(2):287-322, 2004.

GOMES, Mércio Pereira. Os índios e o Brasil: passado, presente e futuro. São Paulo: Contexto, 2012.

HERNANDO, Almudena et al. História recente e situação atual dos Awá-Guajá. In. HERNANDO, Almudena; COELHO, M. E. B. (Org.). Estudos sobre os Awá caçadores-coletores em transição. EDUFMA. São Luís, 2013.

MONSERRAT, Ruth Maria Fonini. Línguas indígenas no Brasil contemporâneo. In: GRUPIONE, Luís Donisete Benzi (org.). Índios no Brasil. Brasília, ministério da Educação e Desporto, 1994.

MORENO, Alejandro. Superar a exclusão, conquistar a equidade: reformas, políticas e capacidades no âmbito social. CLACSO, Consejo Latinoamericano de Ciencias Sociales. Buenos Aires, 2005.

OLIVEIRA, João Pacheco de. Uma etnologia dos "índios misturados"? Situação colonial, territorialização e fluxos culturais. MANA 4(1):47-77, 1998. 